\title{
La libertad como bien colectivo en El rastro de la canela, de Liliana Bodoc
}

\section{Liberty as a collective good in Liliana Bodoc's El rastro de la canela}

\author{
Analía Roxana Peruzzi \\ Instituto de Educación Superior № 9-011 “Del Atuel”, Argentina \\ analia_peruzzi2006@yahoo.com.ar \\ Recibido: 25/04/2021. Aceptado: 04/06/2021.
}

\begin{abstract}
Resumen
Este trabajo tiene como propósitos indagar en las técnicas de caracterización de los personajes de la novela El rastro de la canela de Liliana Bodoc, y analizar el impacto de esos caracteres en la identificación o extrañamiento que promueve el texto en el lector. La manera en la que ingresa el conjunto de rasgos del carácter del personaje resulta una puerta de acceso para develar al autor implícito de la obra y sus intenciones en cuanto a la relación que establecerán luego los lectores con sus personajes. Centrarse en las categorías de personaje y perspectiva ayuda a comprender por qué el lector puede sentir simpatía o antipatía, estar de acuerdo o en desacuerdo con los seres de ficción que el texto despliega. El análisis de esos aspectos nos conducirá a observar cómo la novela tematiza el problema de la libertad.
\end{abstract}

Palabras clave: Liliana Bodoc; novela histórica; revolución; libertad

\section{Abstract}

This paper studies the characterization techniques in the novel El rastro de la canela by Liliana Bodoc; and analyzes the impact of these characters on the identification or differentiation that the text promotes in the reader. The presentation of the set of character features reveals the implicit author of the work and his intentions regarding the relationship that the readers will later establish with the characters. Focusing on the character and the perspective categories helps to understand why the reader may feel like towards some characters or dislike towards some others. The analysis of these aspects will show how the novel treats the subject of liberty.

Keywords: Liliana Bodoc; historical novel; revolution; liberty 
El rastro de la canela se publicó en 2010 en coincidencia con las celebraciones del Bicentenario de la Revolución de Mayo en la República Argentina ${ }^{1}$. Fue escrita por encargo y fue la misma Liliana Bodoc quien, poco antes de su lamentable muerte en 2018, explicó qué fue lo que tuvo en cuenta para dar vida a esta novela. En el marco de su relanzamiento en 2016, dijo que, más allá de su interés por rescatar situaciones y personajes históricos, lo particular de un tiempo pasado y distante de nosotros, le interesan también "los universales, esos que atraviesan claramente los tiempos, claramente las épocas, claramente las revoluciones, los mares y nos igualan de tal manera extraordinaria que a mí siempre me sorprende" (Bodoc, 2016). Además, refiriéndose a sus motivaciones fundamentales para emplazar la acción en la agitada Buenos Aires de comienzos del siglo $\mathrm{XIX}$, declaró lo siguiente:

Es nuestra revolución, ¿no?, es nuestra revolución con todos los "peros" que después le podemos y debemos poner. Pero yo creo que hay ahí una latencia, una matriz de la que venimos, mestiza, mezclada, ambigua, confusa, adonde están conquistadores, está la negritud, están los afroamericanos - $\tan$ tremendamente abandonados en la historia argentina, como si no hubieran existido- y por supuesto, los pueblos originarios (Bodoc, 2016).

Creemos que en esas palabras Bodoc alude a procedimientos cuya articulación es fundamental en la construcción de El rastro de la canela: por una parte, la reconstrucción de un pasado histórico, la representación de aquello que lo singulariza y lo hace distinto de nuestra época; por otra parte, el señalamiento de algo que lo acerca a nosotros, eso que Bodoc llama "lo universal", eso que permite que nos reconozcamos en algunos personajes del pasado o nos diferenciemos de otros, facilitando así el tercero de los movimientos puestos en juego: hacer lugar, a través de la ficción, a personajes olvidados por la historia que ha irrigado nuestro

1 Tuve la oportunidad de conversar un par de veces con Liliana Bodoc en eventos académicos. Gracias a Liliana Bodoc por la generosidad para abrir los entramados de su obra y de su vida. Por siempre, en el corazón de tus lectores. En el Anexo, he querido compartir la dedicatoria que una vez me firmó. 
sentido común o, como ha dicho la misma Bodoc en otro sitio, “[...] pensar los intersticios de la historia, los lugares en los que la historia se agrieta y deja pasar la ficción" (Bodoc, 2017).

Este artículo se propone analizar esos procedimientos prestando especial atención a las técnicas de caracterización de los personajes de la novela y al impacto de esos caracteres en la identificación o la toma de distancia que promueve el texto en sus lectores. Se pretende contribuir al conocimiento de la obra de Bodoc a través del acercamiento a una novela suya que ha sido poco estudiada por la crítica académica y en la que, sin embargo, es posible encontrar rasgos parecidos a los de La saga de los Confines, su obra más aclamada por el público y la crítica: la importancia de la libertad como tema (Sagrillo, 2014), la presencia de un héroe colectivo que lucha en la búsqueda y en la recuperación de ese valor (Difabio, 2001); la caracterización de los personajes a través de oposiciones que colaboran en la representación de un "nosotros" y un "los otros" (Sagrillo, 2014), y la construcción de una propuesta discursiva en la que la autora pretende que el lector adhiera a un mundo en el que son escuchadas las voces de los seres marginados (Sagrillo, 2014).

Las categorías fundamentales para el análisis son las de "carácter" y "perspectiva" $y$, como se trata de herramientas narratológicas muy difundidas, podemos explicarlas rápidamente. Entendemos por carácter "el conjunto de atributos que constituyen el 'contenido' o la 'forma de ser' del personaje", cosa que puede describirse haciendo alusión a rasgos que operan en cuatro dimensiones: física, psicológica, social y moral (García Barrientos, 2012: 196)². El estudio de la construcción de personajes,

2 Si bien el libro de García Barrientos (2012) se titula Cómo se comenta una obra de teatro, algunas definiciones y herramientas teóricas que propone para el personaje y el carácter son perfectamente traspolables a la novela. Lo mismo cabe decir de la noción de perspectiva. Para estas operaciones de traspolación o transposición teórica, que han ocurrido siempre entre la dramatología y la narratología, hemos tenido en cuenta lo siguiente: cuando los aspectos del contenido narrativo (historia, fábula o diégesis) se encuentran teóricamente tratados independientemente de su modo de expresión (modo narrativo vs. modo dramático), es decir, haciendo abstracción de su modo de expresión, puede realizarse una transposición directa. Cuando las categorías están teóricamente elaboradas teniendo en cuenta el plano de la expresión (que en el drama es una escenificación y en la narración es un acto de enunciación por parte de un sujeto narrador), las categorías muchas veces también pueden trasladarse, pero haciendo los ajustes y "traducciones" pertinentes. En esto seguimos al propio García Barrientos, 
entendida como procedimiento artístico, entraña la necesidad de prestar atención a la red de relaciones que se configura entre ellos, de tal manera que cada uno se define en función de los demás. Esto equivale a decir, como aconseja García Barrientos (2012: 188), que el analista debe prestar atención al sistema que conforman los personajes o a su "dinámica de grupo", en palabras de Bourneuf y Oullet (1983: 171). Junto con otros procedimientos narrativos, esa dinámica que se genera entre los diversos caracteres es uno de los aspectos que mayor incidencia tienen en la perspectiva afectiva e ideológica que asume el autor que nos figuramos y que promueve identificaciones o tomas de distancia de parte de los lectores ${ }^{3}$.

Partimos de la hipótesis de que, en El rastro de la canela, uno de los principales aspectos que provocan tensiones entre los personajes y estimulan reacciones en los lectores es la forma en que aquellos se posicionan frente al valor de la libertad. La novela promueve en el lector sentimientos de identificación y adhesión al sistema de ideas de los personajes que persiguen la libertad entendida como bien social, mientras que genera relativa antipatía y desacuerdo con aquellos que la pretenden con el propósito de obtenerla solo para sí mismos.

\section{El argumento y el sistema de personajes}

Antes de entrar en el análisis, hace falta una breve síntesis del argumento. La novela se remonta a principios del siglo XIX, durante épocas

que explica estas cuestiones metodológicas en su transposición al drama de muchas categorías provenientes de la narratología de Genette, así como la exposición sintética de Abraham (2017).

3 Como precisa Abraham (2017: 10-14), esas nociones de perspectiva o focalización afectiva e ideológica están ausentes en la narratología sin dudas más canónica: la del Genette de Figuras III, quien se limita a considerar la perspectiva atendiendo solamente a las dimensiones cognoscitiva y sensorial. Sí están presentes, en cambio, en Bajtín, quien se refiere fundamentalmente a ese tipo de reacciones afectivas e ideológicas cuando habla del punto de vista (puede verse Drucaroff, 1996: 85-108). También figuran en García Barrientos (2012: 267-275), cuya sistematización transponemos al modo narrativo. En la perspectiva afectiva, los polos de identificación versus extrañamiento (toma de distancia, diferenciación) toman la forma de simpatía (identificación con un personaje) y antipatía (extrañamiento respecto de un personaje). En la perspectiva ideológica, que atañe a la visión de mundo y los sistemas de valores sostenidos por los distintos agentes del mundo narrado, la identificación se resuelve como estar de acuerdo con, mientras que el extrañamiento consiste en estar en desacuerdo. 
del Virreinato de las Provincias del Río de La Plata, y cuenta una historia en la que se entrelazan la política y el amor.

Del amor de Don Hernando Encinas y su esposa Inés nace Clara y, veinte años después, Amanda, quien ha heredado la belleza de su madre y se convertirá en la protagonista femenina de la historia. En 1789, Clara contrae matrimonio con un caballero español de buena posición económica, don Eladio Torrealba. Al cabo de un tiempo, es madre de un niño de precaria salud llamado Fausto, que se lleva poca diferencia de edad con su tía Amanda.

Promediando 1790 don Hernando Encinas decide partir a San Sebastián de Río de Janeiro junto a su esposa e hija menor, ya que doña Inés ha recibido de un tío materno una importante hacienda en la región del oro. Clara, en cambio, permanece con su esposo y su hijo en Buenos Aires. En su partida, la familia lleva consigo a la esclava doméstica María; mientras que a modo de obsequio le dejan a su hija mayor otra esclava más joven: Fátima.

Un día llega a Buenos Aires una carta en la que don Hernando le anuncia a su hija mayor el fallecimiento de su madre. Con tan solo seis años, Amanda se aferra a su nana María y crece en libertad en la hacienda. Años después, ante su inminente muerte, don Hernando le solicita a Clara que cuide a su hermana.

En 1808, María y Amanda ya se encuentran viviendo en la misma casa junto a la familia Torrealba. En este escenario, la nana de la muchacha se entera, por boca de las demás mujeres de la cocina, de que en la estancia vive un hijo ilegítimo de don Eladio producto de la relación con una joven esclava -ya fallecida- Ilamada Veridiana Tatamuez.

El amor entre Amanda y Tobías Tatamuez no tarda en aparecer. Mientras tanto Fausto, quien también pretende la atención de la muchacha, mira con resentimiento y envidia a su hermano mulato.

La estadía en el hogar familiar del viudo don Eugenio Montesinos, rico comerciante español a quien Clara quiere casar con Amanda, coincide con la acusación a Tobías Tatamuez de sedición contra el virrey Baltarsar 
Cisneros. Frente a la orden de detención, el mulato es apresado, no sin antes disparar contra las fuerzas reales, y es encarcelado. Don Eladio mueve sus influencias para que el Juzgado de Vigilancia Política conmute la pena de muerte por otra más leve, y finalmente logra que su hijo sea deportado a Montevideo bajo la condición de no regresar por ningún motivo.

Ronda 1810 y los aires de revolución se sienten en las colonias. Don Eugenio y Amanda contraen nupcias, luego partirán a la Península. Cuando pasan por el puerto de Montevideo, a la reciente novia la espera Tobías. El hidalgo español prosigue su marcha y se despide de la joven pareja, feliz de haberla ayudado.

Pasa el tiempo y el germen iniciado en 1810 va creciendo en las Provincias del Río de la Plata, que son el escenario de las guerras de la independencia. Tobías participa activamente mientras envía cartas a su esposa preguntando por su hijo.

En este escenario, la autora recupera la imagen de los Chisperos como uno de los agentes necesarios en los sucesos que desembocaron en la destitución del representante político del poder español en las tierras del Virreinato del Río de la Plata. O’Donnell (2015) sostiene que la historiografía liberal y oligárquica reduce o niega la participación popular en los hechos de nuestra historia. Recuperando la participación de los negros en nuestra historia y la de los Chisperos en nuestra revolución, el planteo realizado por Bodoc propone un contrapunto con ese discurso histórico que relegó a un segundo plano la acción de estos grupos del pueblo bajo. $Y$, en consecuencia, la dimensión social de los caracteres desempeña en la novela una función fundamental en la construcción del sistema de personajes.

Tanto la familia Encinas como la familia Torrealba integran la élite porteña, ya que su origen español es el pasaporte para ocupar los lugares privilegiados en la jerarquía heredada de la conquista en América. Se dedican al comercio, tienen extensas propiedades que les permiten vivir cómodamente y sus derechos son reconocidos por la justicia. 
Por su relevancia en la acción y su figuración en los diálogos, Amanda es la elegida dentro de la clase social alta para ocupar el lugar de protagonista. A partir de ella es posible recuperar la historia de amor entre sus padres, cómo fue su niñez, su vida en las tierras rioplatenses mientras estaba en la casa de su hermana, hasta llegar a su condición de madre y esposa.

Otro de los personajes ligados a la familia Torrealba es don Eugenio Montesinos, comerciante que realiza transacciones con las colonias. Su estadía en la casona de su compatriota don Eladio lo lleva a entablar una relación paternal con Amanda Encinas. Pero como se verá en el apartado de la caracterización de los personajes, si bien por su actividad económica tiene conexión con la clase alta, se distancia de ellos en su forma de interactuar con hombres libres y esclavos.

En esta última categoría se ubican María, Fátima, el Tisiquito y un grupo de once hombres y mujeres que llevan a cabo diversas tareas domésticas y agrícolas en las propiedades de las familias Encinas y Torrealba.

La narradora no brinda información sobre la familia de la negra María. Además de cumplir como nana de Amanda debe responder a las órdenes de Fátima, que es quien tiene la autoridad sobre las mujeres del servicio doméstico. La relación entre ambas es tensa y poco cordial:

-iCierren el pico, atrevías! -ordena a sus dos ayudantes. Y enseguida se dirige a María con brutalidad-: iUsté presuma, que ya le voy a enseñá que aquí el enemigo de Fátima vale meno que un perro!

María limpia el plato con un trozo de pan. Lo come sin apuro. Y cuando acaba, mira a Fátima. Un extraño sonido comienza en su garganta. Crece y cobra cuerpo. Primero la negra gruñe, después ladra (Bodoc, 2010: 107).

Entre María y los integrantes de la familia Torrealba prácticamente no hay trato. No se incluye ningún diálogo entre la señora Clara Encinas de Torrealba y María. Incluso cuando Fausto pretende golpear a la esclava que pertenece a su prima, la actitud pasiva que asume la dueña de casa indica el consentimiento expreso de ese tipo de maltrato al que se somete a la servidumbre: “Escúchame bien, negra. No sé cómo fuiste enseñada, pero 
aquí no interrumpes una conversación de tus amas y, mucho menos, haciendo monerías por la ventana. iAquí no!, ċlo entiendes? Amanda va a intervenir, pero su hermana mayor la sostiene por el brazo (Bodoc, 2010: $35)^{\prime \prime}$.

Fátima, la esclava más joven, mantiene una relación distinta con su amo Fausto a quien ha criado desde pequeño. Entre ambos existe un pacto: "Fátima escucha y cuenta. A cambio, Fausto le da monedas que ella guarda celosamente para, algún día, comprar dos libertades: la de su hijo varón y la suya propia" (Bodoc, 2010: 51). De esta manera Fausto Torrealba garantiza la estabilidad entre el mundo de los amos y el de los subordinados. Cualquier señal de insurrección en este sector implica un peligro para el orden instaurado, por lo que el castigo es la forma de sanción que sirve para encauzar a quienes se rebelan contra las rígidas jerarquías sociales. En el ámbito privado, la mano ejecutora es la de un negro que "tiene el látigo": su "libertad reside en tomar una paga por sus oficios de capataz sobre los once esclavos de la familia" (Bodoc, 2010: 67).

Otra mujer que pertenecía a la familia Torrealba es Veridiana Tatamuez, una bella joven que adquiere don Eladio y con la que engendra a Tobías. Este hecho desencadena la vergüenza que padece en sociedad Clara Encinas de Torrealba y el profundo resentimiento de Fausto hacia el mulato "que nació para vergüenza de su familia, en mala hora, y de mala madre" (Bodoc, 2010: 50).

El hijo ilegítimo de don Eladio y Veridiana Tatamuez es el resultado de la amalgama de dos mundos, el de los amos y el de los esclavos: "El mulato no suele distraerse, escucha lejos, percibe el cómo y el porqué de las sombras. Ha crecido siendo parte de dos mundos, y aprendió de los hombres libres tanto como de los esclavos. Eso le permite ver, oler y escuchar de dos maneras. Y le otorga, repetido, el don de la sagacidad" (Bodoc, 2010: 63).

La condición de mestizaje de la que es producto Tobías Tatamuez no es bien vista por la sociedad colonial, son considerados una casta inferior y están imposibilitados de ocupar cargos públicos y grados en los ejércitos. Su figura se recorta entre quienes viven en el sector de los esclavos, para 
ocupar un papel fundamental en la trama. Su situación de "negro libre" le permite moverse con mayor independencia que los hombres y mujeres atados generacionalmente a sus dueños. En el siguiente diálogo con Amanda, surge la curiosidad de la joven por saber si los "negros libres" pueden ir a los festejos en honor de Fernando VII. Pero en este intercambio se pone de manifiesto el sentimiento de Tobías y la forma en la que él mismo se percibe:

-¿¿Vendrá con nosotros a la celebración? - pregunta Amanda.

- No lo creo.

-Supongo que podría ir. Eladio habló de la familia y de los esclavos, pero no mencionó a...

-A los negros libres - completó Tobías.

-Usted no es negro.

-Claro que sí, señorita. Me gusta ser negro, como lo fue mi madre.

Sus ojos tienen un brillo que Amanda solo vio durante su infancia, en los esclavos prófugos que traían de regreso y soportaban en silencio los castigos (Bodoc, 2010: 78).

Contrariamente a lo que se espera de una joven de la élite, Amanda se enamora de Tobías Tatamuez. El amor que siente por él deja de ser invisible a los ojos de su primo Fausto y este es un motivo más para alimentar la envidia que lo carcome contra su hermano.

La información que brinda la narradora sobre las normas sociales permite comprender la gravedad que provoca transgredir los límites fijados:

En el año 1808, el amor debía atenerse a ciertas normas y razones. Si eres así, así debes casarte... Si te apellidas de este modo, únete a un apellido semejante... Si pones cubiertos en tu mesa, busca a quien ponga candelabros.

Si él es un mulato, no camines a su lado ni comas con él limas dulces.

Si ella pertenece a la familia del amo, no le quites el jugo que le moja los labios (Bodoc, 2010: 87). 
En medio de estas prohibiciones, se lleva a cabo la lucha de "un mulato y una blanca" para estar juntos. Por suerte, algunos personajes actúan a favor de la pareja, como es el caso de la esclava María que manifiesta su amor maternal a la más pequeña de la hermanas Encinas; da su vida por protegerla y sostenerla en los momentos más difíciles. En cambio Fátima rechaza a Tobías Tatamuez por su naturaleza impura nacida de la unión entre un blanco y una negra.

Doña Clara, Fausto y Fátima se presentan en oposición a Tobías Tatamuez. Por el contrario Amanda, María y don Eugenio Montesinos colaboran en la resolución favorable de las situaciones de conflicto a las que se enfrenta el mulato que asume el papel de protagonista. La narradora va generando estos contrastes para darnos a conocer los caracteres de los personajes y la polarización política de la época representada en la novela. En el marco de esas condiciones sociales, los personajes entran en tensión alrededor de una antinomia: defender el orden virreinal o romper con estas estructuras políticas y culturales que se erigen como obstáculo de las libertades de los grupos desprotegidos.

Una de las principales oposiciones es la que se da entre Tobías Tatamuez y Fausto Torrealba, que se diferencian no solo por su apariencia sino también porque, mientras el mulato pretende la emancipación del yugo español, el joven criollo se aferra a la idea de que la corona siga siendo quien dirija los destinos de las colonias en América. El joven Torrealba defiende con ahínco las ideas imperialistas de la Corona española porque su visión de la política está teñida por los sentimientos negativos de sus relaciones familiares: "Para él, un gobierno criollo es idéntico a la lujuria de una esclava revolcándose con su amo; y el partido patriota es un mulato ilegítimo. Mientras que el orden virreinal, en cambio, es su madre bordando, por siempre, en la quietud del atardecer" (Bodoc, 2010: 108). Entre ambos nunca será empleada la palabra "hermanos" (91).

Por otro lado, en la misma jerarquía social, hay dos mujeres que actúan y piensan muy distinto: Amana y Clara. Clara Encinas de Torrealba cumple su papel de madre y esposa tal como la tradición lo indica. Su forma de relacionarse con los demás personajes está determinada por lo que la 
sociedad de la época espera y exige de una señora de buena estirpe. Asumiendo una actitud maternal, trata de enseñarle a su hermana, recién llegada de Brasil, comportamientos adecuados y elecciones acordes a la categoría de una mujer civilizada. Por esas mismas razones, es capaz de ocultar la vergüenza que le produce saber que su marido tiene un hijo nacido de la relación con una esclava: "Una ofensa que ella soportaba y soportaría en silencio. Pero que la llenaba de rencor" (Bodoc, 2010: 9). Amanda, por su su parte, es muy diferente de su hermana mayor y desafía las normas sociales con la inocencia de su juventud y la búsqueda del amor.

No siempre las diferencias entre personajes son tan explícitas y manifiestas para el lector; a veces es preciso inferir esas relaciones de oposición, como sucede entre Tobías y la esclava Fátima. Él aspira a concretar su deseo de que todos los hombres sean libres, se preocupa (y ocupa) especialmente por los que son injustamente olvidados por las leyes. Desde Salta, escenario de la batalla que se lleva a cabo en 1813 contra las tropas realistas, Tobías le escribe a Amanda: "Aquí se aprende a ver que la patria aún no iguala a blancos y morenos. Lejos de eso, son mis hermanos los primeros en caer y los que poca gloria reciben. Si eres negro o pardo o mulato, tu valentía y tu sangre valen menos. Esto duele y desilusiona" (Bodoc, 2010: 181). Fátima también tiene el objetivo de conseguir la libertad, pero lejos de cuestionar el régimen imperante, lo hace acatando las reglamentaciones en torno a la manumisión de los esclavos. Fátima repudia el accionar rebelde del hijo de Veridiana Tatamuez; elige en cambio trabajar para el amo Fausto recibiendo las monedas que representan la posible obtención de la libertad para ella y su pequeño hijo.

El análisis realizado permite concluir que, para desentrañar la construcción del sistema de personajes que propone la autora, es fundamental hacer foco en la dimensión social del carácter atendiendo a las relaciones establecidas en la época que se cuenta. Es posible identificar dos grandes grupos de personajes: uno, formado por los sujetos de la clase dominante y el otro, por los dominados. Dentro de cada uno de ellos, se hallan ciertos personajes que defienden el orden social establecido y otros que se rebelan contra las coacciones que han sido grabadas desde la historia de sus ancestros (ver tabla en el Anexo). Los personajes reaccionan 
e interactúan en el marco de las normas que rigen el entramado social en los tiempos del Virreinato del Río de la Plata. No obstante, mientras que la jerarquía de los personajes por sus grupos sociales es representación histórica; la jerarquía de los personajes según la función novelesca es creación de la autora y constituye uno de esos resquicios por donde "la historia se agrieta y deja pasar la ficción" (Bodoc, 2017). La decisión de otorgar el protagonismo a quienes se rebelan y actúan para romper las barreras estamentales pone en evidencia la simpatía de Bodoc por la transformación de la estructura social de la época.

\section{La caracterización de los personajes}

En los parágrafos anteriores se priorizó el análisis de la dimensión social del carácter, ya que este aspecto permite sistematizar mejor las relaciones que se entablan en el sistema de personajes. En el presente apartado se abordarán las dimensiones física, psicológica y moral. Además, se identificarán las técnicas de caracterización que emplea la escritora para dar vida a los seres de la ficción.

Al hacer referencia a su labor en torno a la construcción de los personajes, Bodoc manifiesta: "Me interesa mucho la observación de las acciones físicas, descubrir cómo se realiza una acción física, cómo y con qué ritmo reaccionás ante determinado estímulo. Hago observaciones del prójimo, esto debe venirme del teatro. Pero es muy útil para la verosimilitud de los personajes". Además, la autora destaca la función del nombre propio en la construcción de identidades novelescas: "Los nombres son importantes porque les ponen alma a los personajes" (cit. en Comino, 2004).

Los primeros nombres que se dan a conocer en la historia son los de don Hernando y doña Inés. Ella es descrita por la narradora como una joven de buena familia y de cabello rojizo; él, en cambio, se va dando a conocer por la forma en que se comporta como padre y esposo amoroso y solícito. Ambos padres de las jóvenes Encinas guardan una correspondencia entre su carácter y el significado de sus nombres: Hernando, cuya interpretación 
etimológica remite al valor de la paz, e Inés, que se relaciona con lo sagrado y la castidad.

El intercambio de cartas entre don Hernando y Clara da cuenta de la preocupación que lo aqueja por el futuro de sus descendientes. Por este motivo le encargará a su hija mayor que, luego de su muerte, cuide de Amanda: “Creo que será prudente que la lleves contigo a Buenos Aires. Sin mi cuidado, se transformará en un animalito salvaje, iya verás que algo de eso tiene! Sin embargo, es una hermosa muchacha, dulce y sana, a la que no te costará casar" (Bodoc, 2010: 11). El nombre "Amanda" proviene del vocablo latino "amandus", que significa digno de ser amado, aunque hay quien opina que podría proceder del germánico "ald-mann": hombre ilustre. El onomástico se celebra el 25 de mayo, justamente la fecha que se constituye como eje de la historia.

De Clara, la narradora afirma: "La hija del matrimonio Encinas no heredó el cabello rojizo de su madre ni su porte exquisito" (Bodoc, 2010: 5); pero aún más, no tuvo la suerte de contraer nupcias por amor. Ausencia y negación recaen sobre la imagen de la hija mayor del matrimonio, marcando así su contraposición respecto de la pequeña Amanda, que es como un espejo de su madre: "Esta segunda hija sí heredó el cabello de su madre. $Y$ fue tan semejante a ella como la imagen de un espejo que reflejara el pasado de quien se pusiera delante" (Bodoc, 2010: 6).

A diferencia de su pequeña hermana, Clara Encinas de Torrealba se aferra al conjunto de normas construidas sobre la base de la costumbres de la época colonial y por eso sufre y se enoja con Amanda por su forma "salvaje" de comportarse. Amanda, en cambio, ha crecido en libertad en las tierras de Río de Janeiro. Esta diferencia es resaltada constantemente en el texto por la forma de nominar. Si Amanda no requiere la repetición de su apellido como estrategia discursiva para recordar al lector la procedencia y el estatus social al que pertenece, su hermana doña Clara Encinas de Torrealba es designada repetidas veces de esta manera. La repetición del nombre y los apellidos completos acentúa la caracterización de un personaje que se aferra a todos los símbolos de distinción social. Esta estrategia se emplea con la intención de remarcar los orígenes y el estado 
de casada del personaje; expone su sujeción a la tradición patriarcal y clasista. Esta reafirmación de la identidad evidencia a su vez la necesidad constante que experimenta Clara de ratificar su autoestima y su lugar en la familia.

La segunda pareja femenina que cobra notabilidad es la formada por las esclavas Fátima y María. El espacio doméstico en el que se mueven con soltura es la cocina y "los fondos del terreno donde viven los esclavos" (Bodoc, 2010: 66). Allí, la criada que responde a las órdenes de Fausto Torrealba es quien tiene a su cargo la distribución de tareas a las demás sirvientas; por lo que también la nana de Amanda está bajo su mando.

Fátima es una mujer joven que, de acuerdo a los datos bridados por la narradora, acepta su sometimiento a Fausto Torrealba, el hijo de su ama, pero busca su libertad y la de Tisiquito; por eso resguarda cada moneda que recibe como parte del pacto. Pero su hijo muere y entonces pierde el interés por su libertad y por su vida, a punto tal que solo es capaz de odiar:

Fátima se ha transformado en puro odio. No sabe ni quiere hacer otra cosa más que odiar. Y Tobías Tatamuez es la propia imagen de su desdicha. Fátima ha gastado en chicha todas las monedas que ahorraba para comprar dos libertades. Fátima es un ser de odio que trastabilla a causa del alcohol (Bodoc, 2010: 155).

De María, la narradora cuenta que resaltan sus rulos negros en contraposición a los rojizos de "su niña" Amanda. Las alusiones a su apariencia indican que es una mujer mayor; sin embargo, cuando invoca a la diosa Oxum parece transformarse y recobrar juventud "bailando con la gracia de una moza, envuelta en un mantón amarillo y tintineando las pulseras doradas con los bríos de una reina africana" (99). Es así que se la ve desplegar su poder de conexión con fuerzas de otro mundo. Por eso es como el significado de su nombre: "la elegida por Dios". De las acciones que realiza María, se infiere que no se doblega ante los actos injustos. La mirada firme frente a las amenazas de Fausto es la expresión de la dignidad del personaje porque sabe que no ha hecho nada malo para merecer el golpe de la mano del amo; pero también sabe que está en territorio ajeno y por lo tanto, debe controlar su rechazo hacia el joven Torrealba. 
La pareja masculina que constituyen Fausto, hijo de doña Clara y de don Eladio Torrealba, y Tobías, fruto de Veridiana y su amo, también se conforma desde el contraste y la diferencia. Fausto es un ser miserable y desdichado. Es un hombre atormentado por sus complejos físicos. Las cicatrices en su rostro producidas por la viruela y su endeble salud recrudecen la rivalidad que siente hacia Tobías, y la envidia hacia el mulato se incrementa al ver la relación que tiene su padre con el hijo de la esclava:

Lo mortifica andar junto a su padre y su hermano ilegítimo porque ambos lo sobrepasan mucho en altura. Ambos, además, caminan con pasos largos, y eso lo obliga a doblar su marcha para no quedar rezagado.

Como un pato junto a una garza, así se siente Fausto por culpa de Tobías Tatamuez... (Bodoc, 2010: 50)

Fausto manifiesta irritabilidad y rabia en su carácter, lo que sacia con su sed de infligir dolor y sometimiento en el cuerpo ajeno, especialmente el de los esclavos:

A Fausto, la política se le mezcla con los sentimientos. Para él, un gobierno criollo es idéntico a la lujuria de una esclava revolcándose con su amo; $y$ el partido patriota es un mulato ilegítimo.

Mientras que el orden virreinal, en cambio, es su madre bordando, por siempre, en la quietud del atardecer (108).

El estilo directo pone en evidencia no solo cómo actúa sino también cómo se expresa Fausto. Sus actos de habla son en su gran mayoría órdenes y amenazas. Habla para imponer y para sembrar cizaña en los demás personajes con los que interactúa. Desde la perspectiva de María, Fausto tiene "ojos de culebra" y actúa con perversidad. Esta animalización despliega múltiples sentidos que provienen del símbolo de la serpiente: lengua amenazante, agresividad con sus víctimas y maldad, si se considera la imagen mítica del animal. En sus oraciones a Oxum, María insiste: "Temo que el odio que vive adentro de Fausto se haga como cien serpientes en el vientre de mi niña, y la seque, la consuma y la deje sola en este mundo" (98). Por suerte, esta solicitud se ve cumplida con la existencia de Tobías y el amor que va naciendo entre Amanda y él. 
La primera referencia al aspecto físico de Tobías la realiza María, quien lo describe como un joven moreno de gran porte, con "una sonrisa ancha y despejada" (21), en cuyo rostro resaltan "ojazos de fuego, tan vivos como la llama" (21). Pero como si su atractivo no fuera evidente ante la nana de Amanda, dos esclavas domésticas quedan admiradas de su belleza y sus buenas maneras. También se detalla su vestimenta: "Ileva ropa ligera y calza unas ojotas de cuero" (48), a pesar del frío de agosto de 1808; lo que denota su situación social. Desde la perspectiva de su padre, es un hombre de confianza, honesto y trabajador. Tal como la etimología de su nombre lo indica: "Yahveh es bueno" o "Dios es bueno", el muchacho se caracteriza por ser solícito con los que requieren ayuda.

Tobías se siente orgulloso de ser negro como lo fue su madre Veridiana. La información que le brinda a Amanda acerca de los dolores que su progenitora sufrió antes de morir da lugar a inferir que su deceso se debió a la epidemia de viruela que azotó al Virreinato del Río de la Plata. Ahora, la madre de Tobías forma parte de la dimensión sobrenatural, de esa en la que viven los espíritus y solo algunos como María tienen la capacidad de funcionar como intermediarios; es una joven vigorosa y hermosa. De ella se había enamorado don Eladio Torrealba, hombre fuerte igual que el hijo engendrado.

Dentro del grupo de los personajes secundarios se destaca Eugenio Montesinos. El carácter de este comerciante español se va descubriendo a lo largo de la intriga. La técnica de caracterización consiste, en este caso, en ir revelando paulatinamente la complejidad del personaje. En cuanto a la apariencia externa se hace mención a su barba, por lo que se puede inferir que un hombre mayor. En lo referente a la dimensión moral de su carácter, como su nombre lo indica, sus acciones lo posicionan como un hombre noble y de buenas intenciones. Tiene una manera paternal de tratar a Amanda. Es ecuánime y equilibrado en la expresión de sus sentimientos. Su experiencia en la vida le ha dado la sabiduría necesaria para observar y distinguir intenciones ocultas en las apariencias. Por esta razón mira con recelo las actitudes de Fausto. 
Su condición de comerciante le ha permitido viajar y conocer otros lugares y costumbres. Su mirada desprejuiciada parte de la intención de reflexionar acerca de la naturaleza del hombre y sus necesidades. Tanto don Eugenio como María manifiestan una sabiduría ancestral que es producto de la comprensión de las acciones humanas y del valor de la libertad en las decisiones que marcan el recorrido vital; debido a esto es fundamental su papel de ayudantes de la pareja formada por Tobías y Amanda para el desenlace feliz de esta historia.

En el apartado IV del primer capítulo, entra en juego el Tisiquito como parte del pacto entre su madre Fátima y el amo Fausto. En este caso, se ha elegido un hipocorístico para designar al niño de trece años que, por su contextura física de extrema delgadez, parece enfermo de tisis. Asimismo, la presencia del sufijo apreciativo refuerza el matiz afectivo que todos los esclavos de la familia Torrealba le dispensan al Tisiquito. Él es el único pequeño del que se sabe en la historia, es el único hijo que le queda a Fátima y es también la víctima de las luchas por la tan ansiada libertad. En el proceso de caracterización, pasa de niño, ser vivo animado, a ser una cosa, un camisón, en el momento de su muerte: “El camisón es un niño que se desmorona sin un quejido. [...] El mulato ya es un prisionero. El Tisiquito ya no es un niño" (Bodoc, 2010: 134). De esa manera, se asiste al proceso de degradación que sufre el personaje, que se había iniciado antes con la animalización -“Los huesos se marcan en la espalda del Tisiquito: dos huesos como aletas puntiagudas y otros como una hilera de guijarros del cuello hasta el inicio de sus nalgas raquíticas" (68)- y finalmente es seguido por la cosificación del niño, que ya es la nada misma, solo una prenda de vestir.

La narradora suma al repertorio un personaje nombrado con el apodo de "El Cartero". En el capítulo II, titulado "Los Chisperos", la narradora brinda la siguiente información: "Lo apodan el Cartero por dos razones: porque lo fue en un tiempo y porque, ya sin serlo, continúa cruzando la ciudad con noticias, recados y proclamas" (113). En este caso no se revela el antropónimo del personaje, por lo que es el lector quien debe recuperar de entre sus saberes previos el nombre de Domingo French, el primer cartero de Buenos Aires, y uno de los hombres que formó parte de la causa 
criolla. Así es descripto: "El Cartero se destaca por la potencia de su voz y el entusiasmo de sus convicciones. Es uno de los que se atreven a soñar más allá de Inglaterra y de Francia. Más allá de la propia España y de Fernando VII" (113). El Cartero es un personaje que forma parte del fondo y del contexto histórico. Es un personaje oculto, que actúa desde las sombras. Es la incógnita por ser descubierta. No se lo ve actuar directamente, sin embargo su poder y fuerza de convocatoria atraen no solo al mulato sino a otros tantos que luchan unidos por las mismas ideas de liberación del dominio de la metrópoli.

En suma, la mayoría de los caracteres se construyen a través de ese juego de oposiciones que destacamos al exponer el sistema de personajes. Tanto los dúos femeninos formados por Clara y Amanda, María y Fátima, como el dúo masculino de Fausto y Tobías, se tejen de manera bastante binaria. Frente a estas parejas de opuestos, en las cuales -en general- hay un personaje moralmente positivo y otro negativo, el lector se ve estimulado a elegir.

\section{La perspectiva afectiva e ideológica}

Tal como se desprende de lo expuesto, los personajes moralmente positivos tienden a ser el grupo formado por Tobías, Amanda, don Eugenio y María. Por lo tanto, es factible suponer que el lector sentirá empatía por ellos y se hará eco de los valores que esos personajes sustentan a lo largo de la novela. En sentido opuesto, el conjunto formado por Fausto, Clara, Fátima y don Eladio, generarán en el lector cierta antipatía que produce el distanciamiento emocional y el rechazo de acciones que están basadas en antivalores como la envidia, el egoísmo, el odio y la violencia. Esos personajes no son simples ni simplistas. La narración nos brinda datos para que comprendamos por qué son como son o por qué actúan como actúan. Es probable que se produzca incluso algún momento de conmiseración o empatía hacia Clara, Fausto o Fátima. Pero, en términos generales, lo dominante hacia esos personajes es la diferenciación y la toma de distancia tanto afectiva como ideológica. 
Además de la caracterización, hay otros procedimientos narrativos destinados a producir esos efectos. Para crear la ilusión de objetividad, la voz autoral hace uso en ocasiones del discurso directo $y$, con esta estrategia narrativa, habilita a que se escuche en vivo y en directo a los personajes. El estilo directo que elige la narradora en la escena del intento del golpe a María por parte de Fausto, y la tortura a la que se somete al Tisiquito, acercan la escena al modo dramático de representación y producen ilusión de realidad, generan en el lector una suerte de efecto de espectador. El receptor se siente compartiendo el espacio y el tiempo de la escena, pero -aunque lo deseara- no puede hacer nada para impedir la crueldad y frialdad del joven Torrealba, sensación que probablemente reforzará sus sentimientos de rechazo hacia las acciones y el modo de ser de Fausto. En el mismo sentido opera el hecho de que, cuando hay algún conflicto, la voz narradora otorgue la palabra en discurso directo a quienes se enfrentan a Fausto o Fátima.

El proceso por el cual el lector se posiciona frente a los personajes y sus valores está vinculado con la construcción del autor implícito. En general, nos identificamos con los caracteres que suponemos positivos para el autor que nos representamos o, como dice Garrido Domínguez: "Llámese alter ego o segundo yo, la misión principal del autor implícito consiste en hacer partícipe al lector implícito de su sistema de valores (morales). Así, pues, funciona como una realidad estrechamente asociada al sentido general, profundo, del texto" (1996: 115). Desde esta posición, el autor implícito "no solo puede entrar en contradicción con el sistema de valores del narrador sino con el propio autor real" (116). Pero ese no es caso de EI rastro de la canela, donde es posible detectar una dinámica armónica entre la autora implícita y la voz narradora heterodiegética que, en este relato, actúa muchas veces como depositaria de la voz del autor (eso que suele llamarse "tercera persona autoral") y por eso hemos nombrado en femenino: la narradora. Incluso hay armonía entre estos procedimientos novelescos y las declaraciones que ha hecho la propia Bodoc por fuera de la novela. 
Todo esto facilita para el lector el reconocimiento de un mundo de valores compartidos. Uno de ellos es la defensa de la libertad entendida como bien invaluable que es clave para la dignidad de los personajes. Este aspecto queda confirmado por una declaración de Bodoc (2016): “[...]a mí me interesa siempre como un gran tópico hablar de la libertad, de la construcción de la libertad, de la complejísima construcción de la libertad individual y colectiva, de cuánto hay que pensar en esto".

Nada mejor que elegir el contexto histórico de la Revolución de Mayo para poner en debate la concepción de la libertad como uno de los universales que atraviesa la historia y la esencia del ser humano. Desde el discurso de los personajes se enfrentan dos visiones de libertad: una es absolutamente individual y la otra se presenta como una construcción social que pone la atención (y la tensión) en la responsabilidad y el compromiso de las generaciones presentes en pos de que los descendientes también gocen de este derecho.

La segunda de estas modalidades de la libertad es la valorada por la autora implícita a través de la empatía que promueve con el personaje de Tobías, quien es una suerte de abanderado de ese y otros valores, como el del mestizaje. Dice Bodoc (2016):

Me gusta escribir mucho sobre el mestizaje étnico -no solo sobre eso, sino también sobre el mestizaje de géneros-, el mestizaje como idea de lo impuro y me parece lo más maravilloso de la tierra, así como lo puro me parece lo más peligroso, así que también un poco este Tobías es un mestizo que está representando eso: la necesidad de la mezcla, necesidad de que confluyan en el mismo caldero todas las culturas.

Tobías es la síntesis de los atributos que aportan la sangre de su madre y la de su padre. De este modo, a través de la información que proporciona la narradora, se identifica la particularidad del mulato: de su padre heredó la habilidad para domar caballos y de su madre "una fuerte propensión al orgullo y a la libertad" (Bodoc, 2010: 59). También de ella obtuvo la fuerza de su cuerpo para danzar al ritmo de los tambores, para tocar la guitarra y trepar techos: "El mulato no suele distraerse, escucha lejos, percibe el cómo y el porqué de las sombras. Ha crecido siendo parte de dos mundos, 
y aprendió de los hombres libres tanto como de los esclavos. Eso le permite ver, oler y escuchar de dos maneras. Y le otorga, repetido, el don de la sagacidad" (63).

Quizás es justamente por su participación de esos dos mundos que se le confiere la posición de héroe colectivo de la Revolución de Mayo. En este aspecto es central pensar al personaje en función de la idea de mito fundacional de la república que se desprende de la novela. Bodoc (2017) afirma: "Ios mitos proporcionan una explicación de la realidad, instauran un modelo de comportamiento, una figura heroica, modos de actuar que serían deseables para una cultura". La pregunta es entonces: ¿qué modos de actuar serían deseables? La respuesta podría ser: aquellos que constituyan la búsqueda de derechos fundamentales como la libertad, aquellos que representen los intereses de una comunidad antes que los meramente individuales y aquellos que sostengan la dignidad y combatan la injusticia. Modos de actuar que encarna principalmente el protagonista masculino.

Pero Tobías no está solo. Amanda, como mujer de la época, asume un papel central en la redefinición del concepto de libertad. Ella también experimenta las consecuencias que implica combatir con representaciones cristalizadas en torno al deber ser de una figura femenina y desafía a la tradición patriarcal. Afortunadamente, en su camino hay personajes que creen en la posibilidad de modificar los destinos predeterminados por condiciones económicas y étnicas.

En su estudio acerca de la novela histórica en la Argentina, Lojo (2013: 38) señala que desde la segunda mitad del siglo XX hasta el siglo XXI se evidencia la revalorización del papel femenino y la reinvención de las heroínas como figuras capaces de asumir riesgos y posicionarse en una sociedad que les coarta su albedrío. Asimismo, el lector accede a la perspectiva de los excluidos y a los grupos étnicos silenciados (u olvidados), como los aborígenes y los afrodescendientes. Sostiene la investigadora (2013: 61) que con estas obras literarias "se busca rescatar la interioridad subjetiva de las mujeres y subalternos en general (étnicos y de clase), pero sacándolos de la multitud, el anonimato, el espacio privado, el telón de 
fondo, para dotarlos de personalidades diferenciadas y también de relieve en el espacio público". Así ocurre en El rastro de la canela de Liliana Bodoc.

El lector, si hace el pacto con el plan propuesto por la autora implícita, tenderá a identificarse afectivamente con Tobías y Amanda, y esto tenderá a producir también identificación ideológica con esos personajes que actúan movilizados por ideales nobles que trascienden el plano individual y que constituyen el germen de una nueva identidad personal y social. Por el contrario, personajes como Fausto y Clara movilizarán en el lector cierta antipatía y diferenciación respecto de sus ideas.

\section{Conclusiones}

Con la lectura de El rastro de la canela de Liliana Bodoc se accede no solo a la época de gestación del mito de la Revolución de Mayo, sino también a la vida de personajes que perteneciendo a diversos sectores de la sociedad, representan posiciones diferentes en torno a la idea de libertad.

En el sistema que propone la narración se pone en tensión a los seres de ficción que se hallan en la búsqueda de la superación de las limitaciones que el estamento social les impone. Este es el caso de Amanda, protagonista femenina, que rompe con los mandatos heredados por su condición de mujer de la clase alta.

De manera semejante, desde el mundo de los esclavos emerge la figura de Tobías, que se entrega íntegramente a la obtención de la libertad no solo para él sino para todos los hombres y mujeres que han sido privados de ese valor fundamental. Deja de lado su relativa comodidad, ya que como "negro libre" goza de ciertas ventajas en comparación con los esclavos, para luchar por el futuro de muchos.

Publicada en conmemoración del Bicentenario de la Revolución de Mayo, la novela viene a recuperar el lugar de la población afrodescendiente en las luchas por la independencia del yugo monárquico. Por eso dirá la narradora: "El mulato siente que una victoria de la patria reparará los tormentos que Veridiana ha sufrido". 
Mientras Amanda mece a su niño y sueña con el regreso de Tobías, mientras Tobías ama desde la distancia a su mujer e hijo y combate con hombres y prejuicios; las tierras del Virreinato del Río de la Plata van desintegrando las viejas fronteras y construyendo nuevas... una historia de amor y libertad en mayo de 1810 -así reza el subtítulo de la edición elegida para el presente trabajo- que emana del "fundamental anillo mágico del mito", en palabras de Campbell.

Tobías, hijo de una esclava y de un español, es construido como el héroe de la revolución y su lucha por la libertad individual y colectiva es el símbolo de miles de hombres y mujeres que forjaron los caminos de la actual República Argentina.

\section{Referencias}

Abraham, Luis Emilio (2017). Herramientas de narratología específica: el modo narrativo de contar historias. Documento de cátedra. Mendoza: Universidad Nacional de Cuyo, inédito.

Bodoc, Liliana (2010). El rastro de la canela. Buenos Aires: Norma.

Bodoc, Liliana (2016). "Presentación de El rastro de la Canela". Registro en video de la conferencia pronunciada en el Colegio San Juan El Precursor, San Isidro, Buenos Aires, 30 de junio de 2016. Youtube, 3 jul. Disponible en tres partes: https://www.youtube.com/watch?v=rfb9wLVme8E

https://www.youtube.com/watch?v=ILU2KKIhxUU

https://www.youtube.com/watch?v=43IfBfJNnKY

Bodoc, Liliana y otros (2017). "Los confines de la palabra / Lo mágico". Programa de Canal Encuentro. Encuentro.gob.ar, http://encuentro.gob.ar/programas/serie/8688/7464?temporada=1

Bourneuf, Roland y Réal Ouellet (1990). La novela. Barcelona: Ariel.

Comino, Sandra (2004) "Entrevista a Liliana Bodoc". Imaginaria, n. 132. Disponible en: http://www.imaginaria.com.ar/13/2/bodoc lecturas.htm

Difabio, Elbia (2001). "Lectura intercultural de Los días del venado de Liliana Bodoc". Piedra y canto, n. 7- 8. 53-66. Disponible en: http://bdigital.uncu.edu.ar/2714

Drucaroff, Elsa (1996). Mijail Bajtín. La guerra de las culturas. Buenos Aires: Almagesto.

García Barrientos, José Luis (2012). Cómo se comenta una obra de teatro: ensayo de método. México: Paso de Gato.

Garrido Domínguez, Antonio (1996). El texto narrativo. Madrid: Síntesis. 
Lojo, María Rosa (2013) "La novela histórica en la Argentina, del romanticismo a la posmodernidad". Cuadernos del CILHA, vol. 14, n. 19. 38-66. Disponible en: https://www.redalyc.org/articulo.oa?id=181730583005

O’Donell, Pacho (2015). "La participación popular en Mayo". Página 12, 26 may. Disponible en: https://www.pagina12.com.ar/diario/contratapa/13-273506-2015-05-26.html

Sagrillo, Susana (2014). La otra voz en La saga de los confines: un estudio sobre la trilogía de Liliana Bodoc. Mendoza: Ediunc. 
Anexo

\begin{tabular}{|c|c|c|c|}
\hline & Clases dominantes & \multicolumn{2}{|c|}{ Clases dominadas } \\
\hline \multirow[b]{2}{*}{ 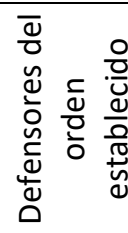 } & \multirow[b]{2}{*}{$\begin{array}{c}\text { Clara Encinas de } \\
\text { Torrealba (antagonista) } \\
\text { Fausto Torrealba } \\
\text { (antagonista) } \\
\text { Don Eladio Torrealba }\end{array}$} & Libres & Esclavos \\
\hline & & & Fátima \\
\hline $\begin{array}{l}\tilde{d} \\
\frac{\tilde{O}}{0} \\
\frac{0}{0} \\
\check{\simeq}\end{array}$ & $\begin{array}{l}\text { Amanda Encinas } \\
\text { (protagonista) } \\
\text { Don Eugenio } \\
\text { Montesinos } \\
\text { (deuteragonista) }\end{array}$ & $\begin{array}{c}\text { Tobías } \\
\text { (protagonista) }\end{array}$ & $\begin{array}{c}\text { María } \\
\text { (deuteragonista) }\end{array}$ \\
\hline
\end{tabular}

Sistema de personajes atendiendo a las relaciones sociales y a la jerarquía en la trama novelesca

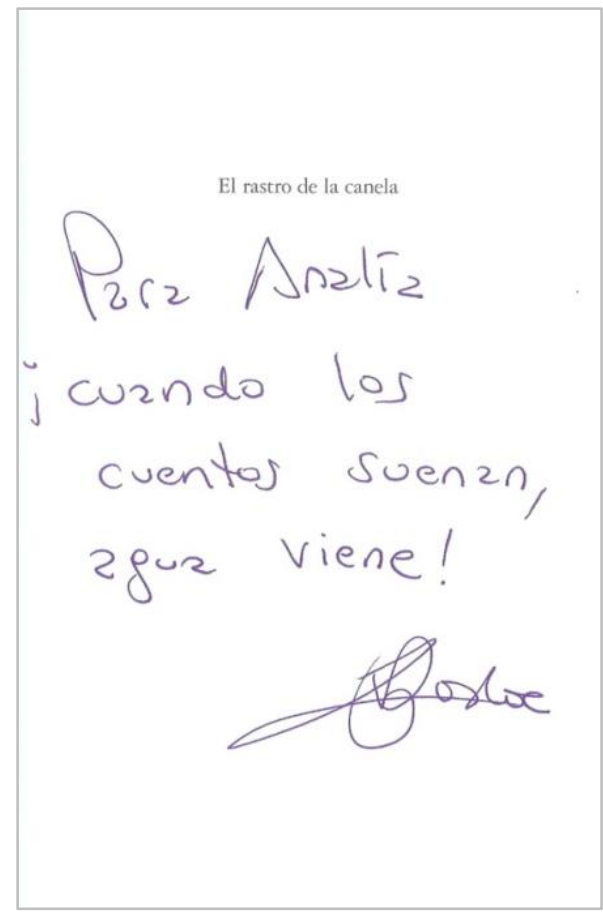

Dedicatoria firmada por Liliana Bodoc 